\title{
Status of Disrespectful and Abusive Maternity Care Among Women who Delivered in Hospitals of Sidama zone, South Ethiopia, in 2019.
}

Berhan Tsegaye Negash ( $\sim$ birieman67@gmail.com )

Hawassa University College of Medicine and Health Sciences

Amanuel Yoseph

Hawassa University College of Medicine and Health Sciences

\section{Research}

Keywords: Disrespect and abusive care, Women, childbirth, Sidama, public hospitals.

Posted Date: August 2nd, 2020

DOI: https://doi.org/10.21203/rs.3.rs-49456/v1

License: (c) (1) This work is licensed under a Creative Commons Attribution 4.0 International License.

Read Full License 


\section{Abstract}

Background: Disrespectful and abusive maternity care is occurred at various degree at health institutions across many countries including Ethiopia. Consequently, maternal mortality remains high in Ethiopia. Despite its importance, information is scarce about disrespect and abusive care. Hence, this study aimed to assesses magnitude and factors associated with disrespectful and abusive maternity care during child birth in public health facilities of Sidama zone, South Ethiopia.

Methods: Facility based cross-sectional study was conducted in sidama zone public health institutions from February 1-30, 2019. We have applied purposive sampling method for selection of health institutions. In addition, study participants were selected by systematic random sampling technique. Data were collected using checklist and exist interview administered questionnaire. Then, we coded, cleaned and entered data through Epidata version 3.1. Finally, exported and analyzed by SPSS. Logistic regression analysis was done to identify association between explanatory variables and disrespectful and abusive care. An adjusted odds ratio with $95 \%$ confidence interval and p-value less than 0.05 was computed to determine the level of significance.

Result: From a total of 577 study participants, only 548 study participants have participated in this study making a response rate of $95 \%$. Magnitude of disrespect and abuse maternity care was $46.9 \%$ [95\% $\mathrm{Cl}$ : 42.8-51]. Marital status of single ( $\mathrm{AOR}=2.6,95 \% \mathrm{Cl}=1.8-6.67)$, four and more births ( $\mathrm{AOR}=4.67,95 \% \mathrm{Cl}: 1.6-$ 12.8), instrumental delivery ( $\mathrm{AOR}=2.63,95 \% \mathrm{Cl}, 1.0-6.6)$, and care provision by female birth attendants $(A O R=1.7,95 \% \mathrm{Cl}, 1.1-2.7)$ were factors positively associated with disrespect and abusive maternity care during childbirth.

Conclusion: Magnitude of disrespect and abusive maternity care is high in this study. Instrumental delivery, female health care provider and four and above deliveries and single marital status were factors associated with disrespect and abuse care. Therefore, government facilities should national health strategies and policies should focus on respectful maternity care. It is also recommended to give intensive training on respectful maternity care especially in public hospitals by involving more female health care provider. Promotion of family planning service can be used as alternative method of reduction of reduction of disrespect and abusive maternal care indirectly.

\section{Plain English Summary}

In 2015 , an estimated 303,000 women lost their lives due to easily preventable pregnancy and child birth related complications worldwide, $99 \%$ of which was contributed by low and middle-income countries. Respectful maternity care advocates suggest that safe motherhood must be expanded beyond the prevention of illness or death to include respect for women's basic human rights including respect for women's autonomy, dignity, feelings, choices, and preference. As the majority of the maternal deaths occur during delivery and immediate postpartum 
periods, increasing skilled birth attendance has been one of the strategies proposed by experts to reduce maternal and neonatal morbidity and mortality. Disrespectful and abusive behavior during child birth is a public health problem, which violates fundamental rights of women and unborn child. Disrespect and abuse treatment during childbirth in health facilities are a burning issue all over the world. Respectful maternity care (RMC) is a universal human right. RMC should routinely practice every woman irrespective her any background and in every health facility around the world. There is limited data on disrespect and abuse during childbirth and maternity care in Ethiopia. Disrespectful and abusive behavior of health workers and other facility staff experienced by women during facility-based childbirth is important, but the little-understood barrier of institutional delivery.

We have assessed prevalence and factors associated with maternal health in Sidama zone, South Ethiopia.

\section{Introduction}

Pregnancy and childbirth is the critical event in the lives of women and their families. It is a time of extreme vulnerability for different complications which endanger the life of women and their children. Hence, women need especial attention at this time [1]. World Health Organization (WHO) reported that 350,000 women die from complications during pregnancy and childbirth. Moreover, an estimated 4.3 million still births or newborn deaths were occurred each year in the world [2]. Globally, sustainable development goals targeted to achieve reduction of the maternal mortality ratio below 70 per 100,000 live births [1]. However, Ethiopia is far from achieving this target. According to 2016 Ethiopian demographic health survey report, maternal mortality ratio was 412 per 100,000 live births [2].

WHO recommends compassionate and respectful maternal care for every woman during birth as the key strategy to attain the highest standards of health care. This includes care throughout pregnancy, childbirth, and postnatal period [3]. Respectful maternity care contains respect for women's basic human rights. For example, respect for women's autonomy, dignity, feelings, choices, and preferences. Besides, companionship with their relatives or partners is mandatory during maternity care [1]. Disrespect and Abuse is currently renamed as mistreatment is categorized as physical abuse, sexual abuse, verbal abuse, stigma, and discrimination, failure to meet professional standards of care, poor rapport between women and providers, and health systems conditions and constraints. Even though coverage of skilled maternal health services has been improved substantially during new millennium era, its quality remains inadequate. This could be amplified by neglectful, abusive and disrespectful maternal health care [4].

Growing evidences show that disrespect and abuse maternal care occurs throughout the world with varying degree and severity $[2,10]$. Moreover, these evidence show that women experience disrespect and abusive care during childbirth [3]. Quality of maternal health service is limited to attain physical safety during institutional delivery, but little attention is given to the in culturally sensitive and respectful care [5, 6]. The ideal skilled birth attendant was characterized by caring, empathetic, supportive, trustworthy, respectful, and empowering. In addition, every woman has the right to receive care by ideal skilled 
provider. However, many women, especially adolescent girls, do not receive the culturally respectful care according to their need [7]. Updated knowledge on disrespect and abusive care is fundamental for all stakeholders to promote direct clinical quality improvement and fundamental basic human rights [7, 8].

Disrespect and abusive care is associated with different causes and consequence. Evidence shows that disrespect and abuse at health facilities have negative effect on women's decisions to seek care for delivery service [9]. The quality of care offered at maternity facilities not only affects pregnant women both emotionally and physically but also has an impact on the long-term health and survival of mothers and neonates [10]. Factors contributing to disrespect and abuse maternal health care include the following factors: health system, provider related, socio-demographic, personal and reproductive health factors. For example, personal factors include: Normalizing of abusive care and knowledge on the right of health care service $[11,12]$. Context of disrespect and abusive maternity care varies among ethnicities and their cultural practices. Sidama is one the largest ethnic group among 80 ethnic groups in South Ethiopia. However, information is scarce on disrespect and abusive maternity care Sidama zone. Moreover, a few previous studies were conducted with inconsistent measurement tool. Besides, they focused mainly on health institution of highly urbanized cities with small population. Finally, the current study was special by measuring disrespect and abusive care through direct observation of care using checklist.

Therefore, this study aimed to assess prevalence and factors associated with disrespect and abusive care maternal care during childbirth in public health institutions, Sidama zone, South Ethiopia.

\section{Methods And Materials}

\section{Study area}

This study was conducted from February to March 30,2019 in Sidama zone, southern nation nationalities and people's regional states of Ethiopia. Sidama zone is bordered with Oromia in the North East, Wolayta in the west and Gedeo in the South. The total population of this zone is estimated to be 2.9 million of which $23 \%$ are women of reproductive age group. It has a population density of 497 persons $/ \mathrm{km}^{2}$. It is divided into 19 woredas and 4 city administrations. Based on 2016 Ethiopian demographic health survey report, facility based delivery was accounted on $25.5 \%$ of the total deliveries in Southern nation nationalities and peoples of Ethiopia. Among these deliveries, almost all (25\%) deliveries were conducted in public health institutions. Most of deliveries in health facilities $(20 \%)$ were performed by midwives/nurses in Southern nation nationalities and peoples of Ethiopia. There are 524 health posts, 127 public health centers, 7 primary hospitals and 1 comprehensive specialized teaching referral hospital. Moreover, there are 83 private and 8 NGO clinics in sidama zone. The estimated number of health professions reached 3539. Among these 51 medical doctors, 258 health officers, 1858 nurses,277 midwives and 1095 health extension workers.

\section{Study design, period and population}


Quantitative institution based cross sectional study was conducted to assess the magnitude of disrespect and abusive maternity care among women who gave birth in public health hospitals in sidama zone, South Ethiopia, from February to march 30, in 2019. All women who gave birth in public hospitals of sidama zone were the source population for this study. Women who gave birth in selected public hospitals of sidama zone administration and presented during the period of data collection were the study population for this study. Moreover, each woman who delivered in the selected hospitals and presented at the time of data collection was the study unit. Women who were unable to communicate at the time of data collection and those who lived less than 6 months in sidama zone were excluded from the study.

\section{Sample size determination and sampling method}

The minimum sample size to meet the objective of this study was calculated by using single population proportion formula. We took three public hospitals (more than $30 \%$ ) as samples purposively. Sample size determination was considered the following determinants: power of the study, precision, baseline magnitude of disrespect and abusive care, quality and the cost of the study. But, we computed sample size in consideration of the following assumptions: The expected magnitude of disrespect and abusive maternity care among women at delivery from the study conducted in public health institutions at Addis Ababa, Ethiopia, in 2015 (78.6\%) [13], 95\% confidence level, and 5\% margin of error. Thus, $n=z^{2} p q / d^{2}$. Then, $n=1.96^{2 *} 0.786(0.214) /(0.05)^{2}$. This computation equals to 258 . Then, multiplying by design effect of 2 and adding $10 \%$ non-response rate. The final sample size was computed as 568 . We purposively select top three hospitals based on their client flow in the last 6 months. So, Hawassa university comprehensive specialized hospital, Yirgalem hospital and Leku hospital were selected for this study. Sample allocation was done using proportional allocation to base on the number of clients who received child health service child health services at each hospitals 6 months preceding data collection period. We applied systematic random selection to select study participants. A sample was taken every 3rd delivery in Hawassa university comprehensive specialized hospital and every 2nd client was taken for both Leku and Yirgalem district hospitals based on their respective sampling interval calculations.

\section{Population}

All women who delivered at selected hospitals in Sidama zone were the target population of this study. Women who gave birth and discharged from the selected hospitals in Sidama zone during data collection period were the study population. Those who were admitted and delivered in the selected hospitals regardless of duration of stay and mode of delivery and type of birth outcome were included in the selected hospitals. But, women who came for other medical complications of pregnancy like abortion, false labor, hemorrhage were excluded from the current study. In addition, clients who were referred to another hospital and those who were seriously ill and unable to give informed consent were also excluded from this study.

\section{Data collection}


Data were collected through direct observation checklist and face to face interview using a structured and pre-tested questionnaire. Disrespect and abusive care was measured by direct observation of its components during delivery using structured checklist. Exit interview was done for women who gave birth in the selected hospitals to identify factors associated with disrespect and abusive care. Seven BSC female midwives were used as data collectors and two MSC midwifery supervisors conducted supervision. Data collectors were recruited from health facilities out of the study health institutions. Data was collected after two days training about techniques of interviewing, data collection procedures, and different sections of the questionnaire. Overall supervision also made by the principal investigators. Data were checked for completeness after data collection.

\section{Measurement}

The main outcome variable of this study was disrespect and abusive maternity care. We adapted the measurement of disrespect and abuse maternal care at delivery from browser and hill tool kit and standards set by maternal and child health integrated program (). We have measured disrespect and abusive maternity care using seven performance indicators and their respective 32 verification criteria. The performance indicators or domains were: physical abuse, detention in the facilities, discrimination based on certain traits of clients, non-consented care, failure to meet professional standards of care, nondignified care and abandonment of care. Study participants were asked to report experiences of each of the seven dimensions of disrespect and abusive care. If a respondent reported experiencing any category of disrespectful and abusive care, she was asked to specify the exact nature of the behavior. If the study participants reported at least one of specific sub-component of each category, they were considered as victim of for disrespectful and abusive maternal care for that category. In addition, disrespect and abusive maternal care is considered for any participant if any one of the seven domain of disrespectful and abusive care was presented. The overall measure of disrespect and abusive maternity care is a binary outcome variable. The independent variables included in this study included the following variables: Socio-demographic charactestics, reproductive health characteristics, health service providers charactestics and health institution charactestics. Socio-demographic charactestics include: Age, place of residence, marital status, ethnicity, educational status, occupation, autonomy and family income. Reproductive health charactestics were antenatal care visit, number of antenatal care, place of delivery, place of antenatal care, complication during pregnancy, type of complication, sex of birth attendant, mode of delivery and length of stay in hospital.

\section{Data quality control}

Questionnaire was first developed in English language and translated into Sidama afoo (local language) and re-translated back to English to keep its consistency. Comparison was done between two versions to assess inconsistent and inaccurate data. Finally, any inconsistent and inaccurate data was re-adjusted accordingly. Both data collectors and supervisors were trained for one day on the aim of the study, techniques of interviewing and component of questionnaire. Supervisors were also trained on how to check the completeness and consistencies of questionnaires filled by the data collectors to ensure the quality of the data. Pre-test was carried out on 28 (5\%) of women who gave birth in Shashemene referral 
hospital in Oromia region. Then, any ambiguity on the questionnaire was checked and corrected based on the result.

\section{Data process and analysis}

Data were cleaned, codded and entered into epidata version 3.1. Then, it was exported and analyzed by SPSS version 24. Descriptive statistics like percentage, mean and standard deviation were used for the presentation of demographic data and magnitude of disrespect and abusive maternity care. Tables and graphs were also used for data presentation. Chi-square distribution were used to see overall association of the outcome variable with its explanatory variable. Hosmer and Lemeshow test was performed for the model goodness of fit. During bi-variate analysis, those independent variables which had p-value less than 0.25 were a candidate variable to multiple variable analysis to minimize the effect of confounding variables. Adjusted Odds Ratio with $95 \%$ confidence interval and $p$-value less than 0.05 value was used to declare significance of the association between independent and dependent variable in the final model of multivariable logistic regression.

\section{Ethical consideration}

Ethical approval was obtained from institutional review board of Hawassa University College of Medicine and Health Science. Additional, permission was also sought from Sidama zone health department and from selected health facilities. Written informed consent was obtained from participants after a detailed explanation of the purpose and benefit of the stud. Any mother who was not willing to participate in the study has not been forced to participate. They were also informed that all data obtained from them would be kept confidential by using codes instead of any personal identifiers and is meant only for the purpose of the study.

\section{Results}

From a total of 568 samples, only 548 study participants gave full response for the questionnaires making a response rate of $96.4 \%$. The mean and standard deviation age of the study participants was 26 \pm 4.4 years (mean \pm SD). Majorities $416(76 \%)$ of the study participants were urban dwellers. Nearly half $257(46.8 \%)$ of the study participants were protestants. Nearly all $526(96.0 \%)$ study participants were married. Two hundred twenty-four 224 (40.9\%) study participants attended primary education. Almost half $(48.7 \%)$ of the study participants were housewives. Urban residents were $76 \%$ from the total study participants (Insert table 1). Majority 513 (93.6\%) of the study participants had history of antenatal care visit for their current pregnancy. Moreover, more than half (53.1\%) of the study participants had 4 and more antenatal care visits for the current pregnancy. Among the total study subjects, three hundred thirty (64.5\%) have followed their antenatal care in health centers. Majority $236(43.1 \%)$ of respondents have a total number of at least one delivery. The most common type of complication, reported by the study participants was prolonged labor by accounting 87 (15.9\%). Most of the study participants $313(57.1 \%)$ delivered through spontaneous vaginal delivery followed by episiotomy $113(20.6 \%)$ in the current study 
Table 1

Socio demographic characteristics of women who gave birth in public health hospitals in Sidama zone, South Ethiopia, in 2018 ( $n=548)$.

\begin{tabular}{|c|c|c|}
\hline Variable & Frequency(n) & Percentage (\%) \\
\hline \multicolumn{3}{|l|}{ Age } \\
\hline $15-19$ & 17 & 3.10 \\
\hline $20-24$ & 137 & 25.0 \\
\hline $25-29$ & 243 & 44.3 \\
\hline $30-34$ & 120 & 21.9 \\
\hline $35-39$ & 25 & 4.60 \\
\hline $40-44$ & 6 & 1.10 \\
\hline \multicolumn{3}{|c|}{ Resident area } \\
\hline Urban & 416 & 75.9 \\
\hline Rural & 132 & 24.1 \\
\hline \multicolumn{3}{|c|}{ Marital status } \\
\hline Single & 20 & 3.60 \\
\hline Married & 526 & 96.0 \\
\hline Widowed & 2 & 0.40 \\
\hline \multicolumn{3}{|l|}{ Religion } \\
\hline Orthodox & 172 & 31.4 \\
\hline Catholic & 61 & 11.1 \\
\hline Protestant & 257 & 46.9 \\
\hline Muslim & 51 & 9.30 \\
\hline Other* & 7 & 1.30 \\
\hline \multicolumn{3}{|l|}{ Ethnicity } \\
\hline Sidama & 235 & 42.9 \\
\hline Wolayta & 93 & 17.0 \\
\hline Amhara & 102 & 18.6 \\
\hline
\end{tabular}

N.B: * other = some ethnic group: Silte, Hadiya, Kenbata, Tigray, Gamogofa, Shinasha, Kefa, Gurage and Gedio; ** other = Adventist and Hawariyat. 


\begin{tabular}{|lll|}
\hline Variable & Frequency(n) & Percentage (\%) \\
\hline Oromo & 82 & 15.0 \\
\hline Other ** & 36 & 6.60 \\
\hline Education & & 20.6 \\
\hline No formal education & 113 & 40.9 \\
\hline Primary (1-8) & 224 & 17.0 \\
\hline Secondary (9-12) & 93 & 21.5 \\
\hline College and above & 118 & \\
\hline Occupation & & 48.7 \\
\hline Housewife & 267 & 11.5 \\
\hline Private employee & 63 & 19.0 \\
\hline Government employee & 104 & 14.2 \\
\hline Merchant & 78 & 6.60 \\
\hline Student & 36 & 31.8 \\
\hline Health care decisions & 174 & 21.0 \\
\hline Mother & 259 & 47.3 \\
\hline Husband/partner & 24 & 10.4 \\
\hline Jointly & 57 & 85.2 \\
\hline Family monthly income & 467 & \\
\hline < 500 ETB & & \\
\hline 500-1000 ETB & & \\
\hline$>1001$ ETB & & \\
\hline N.B: * other = some ethnic group: Silte, Hadiya, Kenbata, Tigray, Gamogofa, Shinasha, Kefa, Gurage & \\
\hline and Gedio; ** other = Adventist and Hawariyat. & & \\
\hline
\end{tabular}


Table 2

Reproductive health, and health institution factors of women who gave birth in public hospitals in Sidama zone, South Ethiopia, in $2019(\mathrm{n}=548)$.

\begin{tabular}{|c|c|c|}
\hline Variable & Frequency $(n)$ & Percentage (\%) \\
\hline \multicolumn{3}{|c|}{ Do you have ANC visits in the current pregnancy } \\
\hline Yes & 374 & 67.2 \\
\hline No & 174 & 32.8 \\
\hline \multicolumn{3}{|c|}{ Perceived quality of delivery care } \\
\hline Excellent & 80 & $14.6 \%$ \\
\hline Good & 248 & $45.2 \%$ \\
\hline Fair & 220 & $40.1 \%$ \\
\hline \multicolumn{3}{|c|}{ Number of antenatal visits $(n=374)$} \\
\hline$<4$ visits & 270 & 72.2 \\
\hline$\geq 4$ visits & 104 & 27.8 \\
\hline \multicolumn{3}{|c|}{ Total number of pregnancy } \\
\hline One & 236 & 43.1 \\
\hline Two & 191 & 34.9 \\
\hline Three & 88 & 16.1 \\
\hline Four and above & 33 & 6.00 \\
\hline \multicolumn{3}{|c|}{ Index birth at health facility $(n=312)$} \\
\hline Yes & 153 & 49 \\
\hline No & 159 & 51 \\
\hline \multicolumn{3}{|c|}{ Complication during delivery } \\
\hline Yes & 166 & 30.3 \\
\hline No & 382 & 69.7 \\
\hline \multicolumn{3}{|c|}{ Type of complication $(n=166)$} \\
\hline Prolonged labor & 87 & 15.9 \\
\hline Hemorrhage & 32 & 5.80 \\
\hline Hypertensive disorder & 33 & 6.20 \\
\hline Other* & 14 & 2.40 \\
\hline
\end{tabular}




\begin{tabular}{|c|c|c|c|}
\hline Variable & Frequency (n) & Percentage (\%) & \\
\hline \multicolumn{4}{|l|}{ Mode of delivery for current birth } \\
\hline Spontaneous vaginal delivery & 313 & 57.1 & \\
\hline Instrumental/vacuum delivery & 38 & 6.90 & \\
\hline Caesarian section & 84 & 15.3 & \\
\hline Episiotomy & 113 & 20.6 & \\
\hline \multicolumn{4}{|l|}{ Sex of delivery attendant } \\
\hline Male & 268 & 48.9 & \\
\hline Female & 280 & 51.1 & \\
\hline \multicolumn{4}{|l|}{ Length of stay in the health facility } \\
\hline Less than one day & 252 & 46 & \\
\hline One up to two days & 238 & 43.4 & \\
\hline Greater than two days & & 58 & 10.6 \\
\hline \multicolumn{4}{|l|}{ Time of delivery } \\
\hline Day time & & 351 & 63.1 \\
\hline Night time & & 197 & 35.9 \\
\hline \multicolumn{4}{|l|}{ Type of health provider } \\
\hline Physician & & 55 & 10 \\
\hline Nurse/midwife & & 411 & 75 \\
\hline Profession unknown & & 58 & 10.58 \\
\hline No one & & 4 & 0.73 \\
\hline Birth before arrival at health institution & & 20 & 3.64 \\
\hline \multicolumn{4}{|l|}{ Referral for current birth } \\
\hline Comes directly to study facility & & 318 & 58 \\
\hline Sent from health post to study facility & & 54 & 9.8 \\
\hline Sent from health center to study facility & & 146 & 26.6 \\
\hline Other** & & 30 & 5.4 \\
\hline
\end{tabular}

Disrespect and abuse maternity care 
The overall magnitude of disrespect and abusive maternity care among mothers who delivered in public hospitals in sidama zone was $46.9 \%$ (95\% Cl: 42.8-51.0) (Table 3). Non-consented care was the commonest form of disrespect and abusive maternity car $(n=2417)$. The increasing in the number of study participants more than the sample size indicates the presence of more than one verification criteria in each domain and being victim in one specific verification criteria in turn make the domain (category) of disrespect and abusive maternity care was done. In short, one study participants could be victim by more than one verification criteria and counted as a separate study participant due to the overlapping nature of the measure of outcome variable. Stigma and discrimination of women is the least problem in the study area $(n=148)$ 
Table 3

Types of disrespect and abusive maternal care among women who gave birth in public hospitals in Sidama zone, South Ethiopia, $2019(n=548)$.

\section{Category of disrespectful and abusive maternal care}

Yes n (\%)

\section{Physical abuse}

a. Kicked

$5(0.009)$

b. Pinched

17(0.03)

c. Slapped

27(0.04)

d. Pushed

8(0.014)

e. Beaten

f. Episiotomy without anesthesia

g. Tied to the delivery bed

h. Other

\section{Non consented care}

a. Abdominal examination

b. vaginal examination

c. episiotomy

d. other

\section{Stigma and discrimination}

a. health workers did not treat me well because of my personal attribute.

b. Health workers discriminate me and my companion due to our personal attributes.

$4(0.007)$

\section{Failure to meet professional standards of care}

a. Health workers talked $p$ negatively about pain and relief

b. Health worker did not respond to my needs

c. I was kept waiting for a long time before receiving service

d. Service provision was delayed due to the health facilities internal problem

$56(0.10)$

\section{Abandonment of care}

a. While in labor

b. While in delivery

c. While experiencing complication 
d. After delivery

e. Other

\section{Detention in the health facility}

Was there detention in heath facility?

$58(0.10)$

\section{Non-dignified care}

a. Shouted at

b. Scolded

c. Threated to withhold service 24(0.04)

d. Called by insulting name

e. Laughed at scorned 62(0.11)

f. Other $128(0.23)$

Factors associated with disrespect and abuse maternity care

The result of logistic regression analysis is presented in table four. Eight independent variables were significantly associated with disrespect and abuse maternity care during binary logistic regression analysis. In a multivariate logistic regression model, the following variables were statistically associated with disrespect and abusive care: Mode of delivery, total number of deliveries and sex of health provider conducting delivery and marital status. Mothers who delivered four and above children had 4.6 fold higher odds of disrespect and abuse than mother who delivered only one child (AOR $=4.6795 \% \mathrm{Cl}$ : $1.69-$ $12.89, \mathrm{p}$-value $=0.003)$, mothers who delivered their baby through instrument had 2.6 times more likely to be disrespected and abused than mothers who delivered through spontaneous vaginal delivery ( $A O R=$ $2.63,95 \% \mathrm{Cl}, 1.05-6.59$, P-value $=0.039)$. The chance of mothers whose delivery by female health provider were 1.75 times higher than their counterparts $(A O R=1.75,95 \% \mathrm{Cl}, 1.14-2.7, \mathrm{P}$-value $=0.011)$. Single women were 2.6 times more likely abused than their counterparts $(A O R=2.6,95 \% \mathrm{Cl}=1.8-6.67)$, P-value < 0.001) (Insert Table 4). 
Table 4

Determinants of disrespectful and abusive care from backward stepwise (Wald) regression analysis of disrespect and abuse among women in Hawassa city health facilities and its explanatory variables, Hawassa Ethiopia, 2018 (548).

\begin{tabular}{|c|c|c|c|c|c|}
\hline \multirow[t]{2}{*}{ Types of variable } & \multicolumn{2}{|c|}{$\begin{array}{l}\text { Disrespect and abusive } \\
\text { care }\end{array}$} & \multirow[t]{2}{*}{ COR $(95 \% \mathrm{Cl})$} & \multirow[t]{2}{*}{ AOR(95\% Cl) } & \multirow[t]{2}{*}{$\begin{array}{l}\mathrm{P} \text { - } \\
\text { value }\end{array}$} \\
\hline & Yes & No & & & \\
\hline \multicolumn{6}{|l|}{ Marital Status } \\
\hline Married & 240 & 285 & 1 & 1 & \\
\hline Single & 20 & 6 & $\begin{array}{l}4.76(1.57 \\
14.45)^{\star}\end{array}$ & $2.6(1.8,6 \cdot 67)^{\star \star}$ & 0.002 \\
\hline \multicolumn{6}{|l|}{ Educational status } \\
\hline No formal education & 63 & 50 & 1 & 1 & \\
\hline Primary & 100 & 124 & $0.64(0.41,1.01)$ & $0.95(0.54,1.69)$ & 0.87 \\
\hline Secondary & 46 & 47 & $0.77(0.45,1.35)$ & $1.78(0.86,3.69)$ & 0.11 \\
\hline College and above & 48 & 70 & $\begin{array}{l}0.54(0.32 \\
0.92)^{\star}\end{array}$ & $1.11(0.45,2.71)$ & 0.82 \\
\hline \multicolumn{6}{|l|}{ Occupational status } \\
\hline Housewife & 128 & 139 & 1 & 1 & \\
\hline Private employee & 33 & 30 & $1.19(0.69,2.07)$ & $1.83(0.83,4.07)$ & 0.13 \\
\hline Gov. employee & 36 & 68 & $\begin{array}{l}0.58 \\
(0.36,0.92) *\end{array}$ & $1.19(0.48,2.91$ & 0.70 \\
\hline Merchant & 39 & 39 & $1.08(0.65,1.79)$ & $1.65(0.78,3.49)$ & 0.18 \\
\hline Student & 21 & 15 & $1.52(0.75,4.07)$ & $2.00(0.78,5.13)$ & 0.14 \\
\hline \multicolumn{6}{|l|}{$\begin{array}{l}\text { Decision about health } \\
\text { care }\end{array}$} \\
\hline Her self & 18 & 6 & 1 & 1 & \\
\hline Jointly & 199 & 268 & $\begin{array}{l}0.25(0.09 \\
0.63)^{\star}\end{array}$ & $0.68(0.20,2.29)$ & 0.53 \\
\hline Husband/partner & 40 & 17 & $0.78(0.26,2.31)$ & $1.26(0.32,5.03)$ & 0.73 \\
\hline \multicolumn{6}{|l|}{ Number of ANC } \\
\hline$<4$ & 128 & 111 & $\begin{array}{l}1.97(1.38 \\
2.81)^{\star}\end{array}$ & $0.79(0.52,1.22)$ & 0.28 \\
\hline$\geq 4$ & 100 & 171 & 1 & 1 & \\
\hline
\end{tabular}




\begin{tabular}{|c|c|c|c|c|c|}
\hline \multirow{2}{*}{$\begin{array}{l}\text { Types of variable } \\
\text { Total number of } \\
\text { delivery }\end{array}$} & \multicolumn{2}{|c|}{$\begin{array}{l}\text { Disrespect and abusive } \\
\text { care }\end{array}$} & \multirow[t]{2}{*}{ COR $(95 \% \mathrm{Cl})$} & \multirow[t]{2}{*}{ AOR(95\% Cl) } & \multirow[t]{2}{*}{$\begin{array}{l}\mathrm{P} \text { - } \\
\text { value }\end{array}$} \\
\hline & & & & & \\
\hline One & 108 & 128 & 1 & 1 & \\
\hline Two & 81 & 110 & $0.87(0.59,1.31)$ & $1.19(0.72,1.99)$ & 0.48 \\
\hline Three & 42 & 46 & $1.08(0.66,1.77)$ & $1.44(0.77,2.69)$ & 0.25 \\
\hline Four and above & 26 & 7 & $4.4(1.8,10.5)^{\star}$ & $\begin{array}{l}4.67(1.69 \\
12.8)^{\star \star}\end{array}$ & 0.003 \\
\hline \multicolumn{6}{|l|}{ Mode of delivery } \\
\hline SVD & 161 & 152 & 1 & 1 & \\
\hline Caesarian section & 71 & 13 & $\begin{array}{l}0.19(0.11 \\
0.36)^{\star}\end{array}$ & $\begin{array}{l}0.47(0.21 \\
1.07)^{\star \star}\end{array}$ & 0.073 \\
\hline Instrumental delivery & 11 & 27 & $2.6(1.25,5.42) \star$ & $\begin{array}{l}2.63(1.05 \\
6.59)^{\star \star}\end{array}$ & 0.039 \\
\hline Episiotomy & 48 & 65 & $1.43(0.93,2.21)$ & $1.39(0.79,2.45)$ & 0.253 \\
\hline \multicolumn{6}{|l|}{$\begin{array}{l}\text { Sex of delivery } \\
\text { attendant }\end{array}$} \\
\hline Male & 92 & 176 & 1 & 1 & \\
\hline Female & 165 & 115 & $\begin{array}{l}2.74(1.94 \\
3.88)^{\star}\end{array}$ & $\begin{array}{l}1.75(1.14 \\
2.71)^{\star \star}\end{array}$ & 0.011 \\
\hline
\end{tabular}

\section{Discussion}

In this study, we investigated the type and magnitude of disrespect and abusive maternity care in client burdened purposively selected public hospitals in sidama zone, south Ethiopia. Five hundred forty- eight (548) study participants were gave full response and included in the final analysis of this study making a response rate of $96.4 \%$. Overall the prevalence of disrespect and abusive maternity care was $46.9 \%$ (95\% $\mathrm{Cl}$ : 42.8-51) of study participants reported that they were victim for at least one category of disrespect and abusive maternity care in the current study. The most common type of disrespect and abusive care is non-consented care followed by non-dignified care.

The magnitude of disrespect and abusive maternity care was significant compared with findings of other studies conducted in Ethiopia: For example, the study conducted in Bahirdar city (67.1\%) [13], Addis Ababa (81.8\%), the capital city of Ethiopia [19]. The current finding is lower than these findings. This indicates that disrespect and abusive care is increasing in health institutions of highly urbanized areas than rural health institutions. The possible explanation for this inconsistency might be associated with less client burden relatively in the current study and the accessibility of compassionate and respectful 
care (CRC) universal training for all health providers in recent years designed by the government to increase quality of care. Moreover, many clients could take some illegal acts as normal in the current study. While some others were not aware of their rights and responsibility So that they could report easily when these violations arise in the study area. On the other hand, the current finding is more than findings in different countries in the word: Brazil, Pelotas (5.1\%) [14], Tanzania (15\%), Kenya (20\%) and Indian (28.8\%) [15-17]. The possible explanation might be due to high burden of clients, poor payment and long working hours could lead health provider for exhaustion. Moreover, lack of strong control of illegal act/any form of abuse/ on clients might contribute for increased abusive care in the current study.

Factors associated with disrespect and abusive maternity care among women who give birth in hospitals. Mothers who delivered four and above children had more chance of disrespect and abuse maternity care than one child. This finding is also consistent with findings study conducted in Kenya which showed that women of higher parity, were three times more likely to be disrespect and abuse [15]. Those mothers who had instrumental delivery were more likely to be disrespect and abuse than those mothers who had spontaneous vaginal delivery. This finding is in line with finding of study conducted in Bahirdar, Ethiopia [13]. The possible explanation for this difference might be due to the fact that women tend to disturb the care given for her unintentionally mainly due to associated pain during instrumental delivery.

Consequently, heath service provider tends to abuse and violet the right of women to reduce the impact of intervention on the health of both woman and fetus. Mothers who delivered by female health provider were more likely to be disrespect and abuse than their counterpart. This finding is consistent with a study conducted in other part of the country [19]. This might be that males tend to deliver women carefully as their reproductive organs are different than women by nature. Hence, the Ethiopian society mainly male develop a culture of most confidential and holding issue secret for the women. But, females developed unnecessary confidence in the condition of women as being similar biological organ and wrong perception of abuses and disrespect as appropriate. Single women were more likely to be disrespected and abused than their counterparts. This finding is inconsistent with findings of other studies [14]. The possible explanation for this inconsistency might be that unmarried women are culturally discouraged to have children and bad attitude of health providers towards them in the current study. Unmarried women also accept the inappropriateness of having children without legal marriage so that they think as they have not legitimate right to seek their human rights at health service. While married women are more sensitive and expect more respect and dignity than unmarried from previous studies.

\section{Limitation}

The current study did not assess magnitude of disrespected and abusive maternity care from health provider perspective. Moreover, measurement of disrespect and abusive care varies across studies due to lack of common standard tool. As a result, comparison of results might be difficult. Some institutional factors were not assessed in this study. Therefore, further studies should be conducted from the health providers' perspective. Moreover, institutional factors might solve the problem of disrespect and abusive maternal care during childbirth if they are studied. 


\section{Conclusion And Public Health Implication}

According to report of this study, prevalence of disrespect and abuse among women who visit health facilities in public health institution in Sidama zone was high. In addition, factors associated with disrespect and abuse maternal care were: Maternal single marital status, instrumental delivery, female skilled delivery attendant and high parity. Therefore, health policy makers should enhance compassionate and respectful care training for maternal health care providers (mainly for females). In addition, skilled delivery attendants should avoid or minimize instrumental delivery by following labor strictly with partograph during childbirth. Furthermore, promoting family planning service and birth spacing can alleviate disrespectful and abusive care during delivery.

\section{Declarations}

\section{Acknowledgements}

The authors would like to thank data collectors and supervisors for their invaluable effort. Our deepest gratitude also goes to participants of this study for their voluntary participation. We are also grateful for Sidama zone health bureau workers for their cooperation to conduct this study.

\section{Funding}

The financial support for this research project was obtained from University of Gondar, Research and Technology Transfer vice president office. The funder had no role in design of the study and collection, analysis, and interpretation of data and in writing the manuscript.

\section{Availability of data and materials}

Necessary data is obtained from the corresponding author on a reasonable request.

\section{Authors' contributions}

BT conceived the study and wrote the proposal, facilitated data collection, analysis, data interpretation, drafted the final report and prepared manuscript. AY participates in data analysis, interpretation and drafting of the final report. All authors read and approved the final manuscript.

\section{Ethics approval and consent to participate}

Ethical clearance was obtained from department of Midwifery, college of Medicine and Health Sciences, University of Hawassa institutional review committee approved after reviewing information sheet and 
letter of approval with reference number was granted. Verbal consent was obtained for each participants before data collection. Moreover, the researcher, who get verbal consent, must sign and date the information sheet to document each subject's consent.

\section{Consent to publish}

Not applicable

\section{Competing interests}

Authors declare that they have no competing interest.

\section{References}

1. Miller S, et al. Beyond too little, too late and too much, too soon: a pathway towards evidence-based, respectful maternity care worldwide. The Lancet. 2016;388(10056):2176-92.

2. Health FMO. Ethiopia demographic health survey key indicator. 2016.

3. WHO. The prevention and elimination of disrespect and abuse during facility-based childbirth. 2015.

4. Bohren MA, et al., The mistreatment of women during childbirth in health facilities globally: a mixedmethods systematic review. PLoS medicine, 2015. 12(6).

5. Milman school of public health, C.U., Disrespect and Abuse during Child birth. 2012, Averting Maternal Death and Disability.

6. University Reserch Co., L., Maternal and Newborn Health. November 2012.

7. Margaret E, Greene O. Delivering Success Scaling up solutions for maternal health. 2013.

8. Ratcliffe H. Creating an evidence base for the promotion of respectful maternity care. Boston: Harvard School of Public Health, Harvard University, Department of Global Health and Population; 2013.

9. Molla $\mathrm{M}$, et al. Disrespect and abuse during pregnancy, labour and childbirth: a qualitative study from four primary healthcare centres of Amhara and Southern Nations Nationalities and People's Regional States, Ethiopia. Ethiopian Journal of Health Development. 2017;31(3):129-37.

10. Organization WH, Fact Sheet Maternal Mortality. November 2016.

11. Ndwiga C, et al., Respectful Maternity Care Resource Package; Community Facilitator's Guide, New York, Population Council. 2014.

12. Windau-Melmer T. A Guide for advocating Respectful maternity care White Ribbon Alliance. Washington, DC: Futures Group, Health Policy Project; 2013.

13. Wassihun B, Level of disrespect and abuse of women and associated factors during facility-based childbirth in Bahirdar town, Amhara regional state,Ethiopia. JUNE, 2017 (Unpublished). 
14. Campbell JC, et al. The intersection of intimate partner violence against women and HIV/AIDS: a review. International journal of injury control safety promotion. 2008;15(4):221-31. 